\title{
Towards the creation of digital library content to study aspects of style in Irish traditional music
}

\author{
Münevver Köküer \\ DMT Lab \\ Birmingham City University \\ Birmingham, UK \\ munevver.kokuer@bcu.ac.uk \\ Peter Jančovič \\ School of Electronic, Electrical \\ \& Systems Engineering \\ University of Birmingham \\ Birmingham, UK \\ p.jancovic@bham.ac.uk
}

\author{
Daithí Kearney \\ Section of Music \\ Dundalk Institute of \\ Technology \\ Dundalk, Ireland \\ daithi.kearney@dkit.ie
}

\author{
Islah Ali-MacLachlan \\ DMT Lab \\ Birmingham City University \\ Birmingham, UK \\ islah.ali- \\ maclachlan@bcu.ac.uk
}

\author{
Cham Athwal \\ DMT Lab \\ Birmingham City University \\ Birmingham, UK \\ cham.athwal@bcu.ac.uk
}

\begin{abstract}
This paper presents our initial work on collection of recordings and related metadata with a view to the creation of digital library content for analysis of stylistic characteristics in Irish traditional music. We focus on ornamentation as this is a decisive stylistic determinant in Irish traditional music. The digital library contains a collection of audio recordings of prominent Irish flute players and metadata related to these recordings, such as manual annotation of onsets and offsets, identity of notes and ornaments, information related to performers and performers' style and make and type of instrument used.
\end{abstract}

\section{INTRODUCTION}

In Irish traditional music, tunes are usually of simple and regular structure, however the tradition allows for and applauds the creativity of the individual musician. The creativity, musicality and style of musicians is expressed through variations in performance, with ornamentation being a decisive stylistic determinant in Irish traditional music. The ability to accurately represent and analyse stylistic features such as ornaments allow for the development of discourse related to several key ethnomusicological questions surrounding music making, musical heritage and cultural change.

In this paper, we outline our initial work towards the creation of a digital library content to study aspects of style through ornamentation. We identify prominent flute players in the Irish tradition and their repertoire of tunes that have been regularly recorded and performed. Initially, we

Permission to make digital or hard copies of all or part of this work for personal or classroom use is granted without fee provided that copies are not made or distributed for profit or commercial advantage and that copies bear this notice and the full citation on the first page. Copyrights for components of this work owned by others than the author(s) must be honored. Abstracting with credit is permitted. To copy otherwise, or republish, to post on servers or to redistribute to lists, requires prior specific permission and/or a fee. Request permissions from Permissions@ acm.org.

DLfM '14, September 12 2014, London, United Kingdom

Copyright is held by the owner/author(s). Publication rights licensed to ACM

ACM 978-1-4503-3002-2/14/09 ...\$15.00.

http://dx.doi.org/10.1145/2660168.2660188. populate the digital library for this project with commercially available recordings. These recordings are drawn from a time span of over a century, include recordings of deceased musicians, and provide some insights into variations in style between eras and geographical regions. We hope that providing such digital library content would serve a community of users from musicians to academics in this domain to develop an understanding of style through the analysis of performances of a core repertoire by a variety of musicians.

This paper starts by introducing the structure of Irish tunes and the types of ornaments. We then describe the collection of recordings and metadata content in the library, providing note annotation in the audio signal as well as any additional information about the audio recordings and performers.

\section{IRISH TRADITIONAL MUSIC}

\subsection{The structure of tunes}

In the Irish tradition, the term 'tune' is used to refer to a melody that is usually composed of parts that may be repeated a number of times. Most tunes contain two parts and tunes with more parts are less common [2].

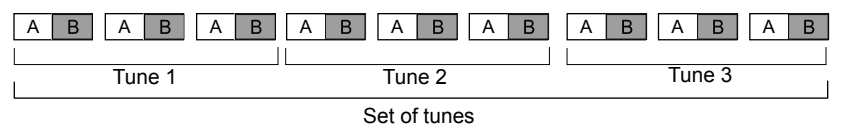

Figure 1: An example of a graphical representation of a structure in Irish traditional music.

In the example shown in Figure 1, each tune has two parts, denoted as an 'A' and a 'B', typically containing eight bars of music in each. Very often a performer will choose three such tunes, usually in different key signatures, that are performed as a continuous piece of music, referred to as 'set of tunes'. This is, in part, influenced by the desired length of a track, usually lasting three to four minutes. It is important that each tune in a set is identified. It may be noticeable 
that while some stylistic features, such as phrasing, are consistent, some ornaments may be used differently in different key signatures.

\subsection{Ornaments}

In Irish traditional music, ornaments are used as embellishments [7]. They are notes of a very short duration and are created through the use of special fingered articulations. Their places are mostly not marked in the score and the choice of their usage usually depends on performer's style.

Ornaments can be categorised as single-note and multinote ornaments. Single-note ornaments, namely 'cut' and 'strike', are pitch articulations. 'Cut' involves quickly lifting and replacing a finger from a tonehole, and corresponds to a higher note than the ornamented note. 'Strike' is performed by momentarily closing an open hole, and corresponds to a lower note than the ornamented note. Multi-note ornaments, namely 'roll', 'crann' and 'shake', consist of a particular sequence of an ornamented note and single-note ornaments. 'Roll' consists of the ornamented note, a 'cut', ornamented note, a 'strike' and then returning to the ornamented note. 'Crann' consists of the ornamented note that is cut three times in rapid succession and then returning to the ornamented note. 'Shake' commences with a 'cut', followed by the ornamented note and a second 'cut' and then returning to the ornamented note. A shorter version of 'roll' and 'crann' omit the starting ornamented note. Figure 2 depicts schematic visualisation of single-note and multi-note ornaments in time-frequency plane.

\section{MUSIC RECORDINGS COLLECTION}

While Irish traditional music is often defined as a 'solo tradition', the development of a commercial recording industry in the United States of America at the start of the twentieth century influenced the introduction of accompaniment instruments, primarily piano and guitar. From these early recordings to the present day, it is unusual to find commercial recordings of single instruments and indeed of a 'solo artist' that does not feature an ensemble of musicians [5]. Despite these trends, the importance of the solo performer in the mindset and discourse in Irish traditional music has not diminished.

At the outset of this project, four prominent flute players were identified as a starting point for the study of style in Irish traditional music: John McKenna, Séamus Tansey, Matt Molloy and Harry Bradley. Two additional flute players have also been added, Michael Tubridy and John Wynne. The selection of recordings spans from 1921 to 2014 and include recordings made in both Ireland and the USA. We also include recordings of some flute tutors developing an awareness of how style is represented. One example of this is Grey Larsen, a well known performer, flutemaker and author [7].

While there are many stylistic differences demonstrated by the musicians documented to date, two fundamental contrasting approaches can be identified - one focusing primarily on rhythm using breath control, articulation and phrasing, the other developing a more ornamented approach using the fingers. McKenna is known for his strong rhythm, achieved using short phrases and rhythmic articulation such as glottal stops, produced by obstructing airflow in the vocal tract. In contrast, Tansey and Molloy utilise long legato phrases and fingered ornaments, appearing to perform many more notes in a tune. Tubridy lies between the two, utilis-
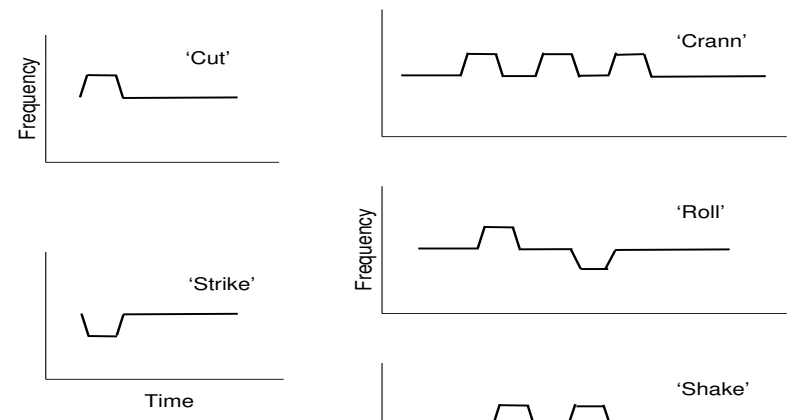

Time

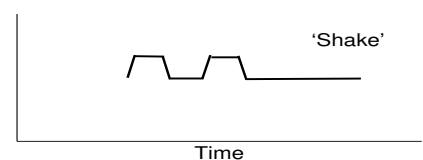

(a)

(b)

Figure 2: Schematic representation of singlenote (a) and multi-note (b) ornaments in timefrequency plane.

ing longer phrases and a more legato style than McKenna but with less ornamentation than Tansey and Molloy. Like McKenna, Bradley's (and Ó Gráda's) style is considered to be particularly rhythmic and he quite forcibly articulates or accentuates the first beat of the bar, creating a constant eighth-note pulse in his dance tunes. Bradley and Ó Gráda produce different tone qualities.

\section{METADATA}

In addition to audio recordings, our digital library also contains metadata relevant for analysing stylistic variations in Irish traditional music. These offer a basis for search to identify and compare cultural and historical contexts of the recordings. The metadata consists of annotation of the content in the audio signal of each recording and information, such as text or image, about each recording and player.

\subsection{Annotation of the audio data}

The original recordings are in uncompressed wav format, stereo, sampled at $44.1 \mathrm{kHz}$ with 16 bits per sample. These are converted into monophonic signal, by summing the signal in both channels.

Manual annotations are created by inspecting the signal using Sonic Visualiser tool [4], loaded with the Aubio Pitch Detector and Aubio Note Detector plugins [3], as well as by listening by an experienced player of Irish traditional flute. Whilst annotation was taking place, the player was able to check the notes by playing the same melody on a flute. The Aubio Note Detector was also used as a playback device to check that the ground truth annotations matched the original recording both in timing and pitch. Figure 3 shows a screenshot from the Sonic Visualiser depicting an excerpt from Maid on the Green played by John Wynne. Both the waveform (top) and the spectrogram (bottom) are superimposed with manually drawn ground truth annotation. The annotation indicates segmentation of the audio signal, where each segment includes the following information: time of onset, time of offset, type of segment, note identity (if applicable), and note frequency (if applicable). The type of segment may be one of the following: note, $16^{\text {th }}$ note, one of the types of single-note or multi-note ornaments, and breath. 


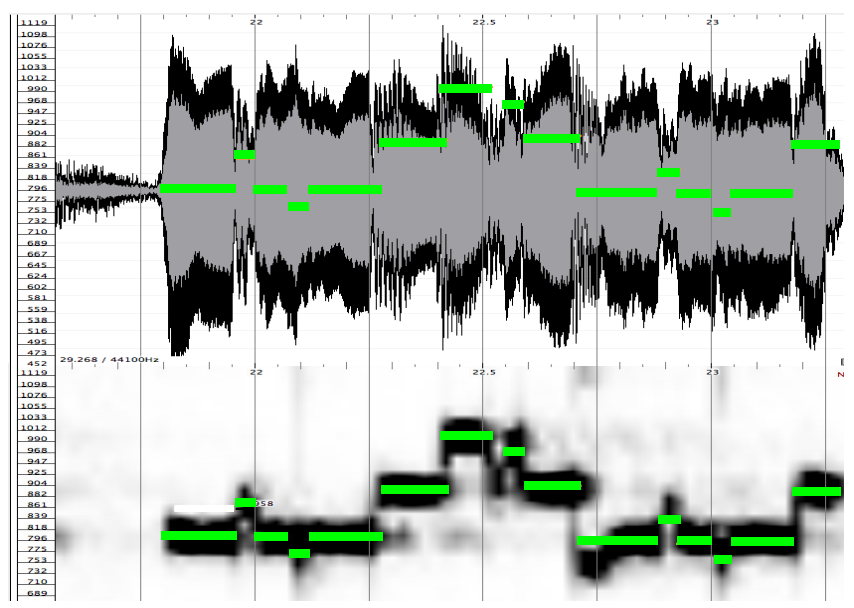

Figure 3: An example of a screenshot from Sonic Visualiser depicting the waveform and spectrogram with indicated manually annotated notes.

The note frequency is determined automatically by the tool based on estimated pitch towards the end of the segment. An example excerpt from an annotation file is depicted in Table 1. This corresponds to a part (starting with $A 5$ note after the initial 'roll') of the audio signal shown in Figure 3. Besides manual annotation, we have also conducted research on automatic detection of ornaments [6].

\subsection{Information on recordings and players}

In addition to ground truth annotations of the audio signal, we also collect for each recording the metadata and contextual information that may be useful for computational analysis or musicological questions. This will contain information about each tune and performer, such as musical biography (and the lineage) of the performer, the main instrument used (its type, maker, material) and, if applicable, information on accompanying instruments present in the audio recording. Any additional metadata, e.g., from the cover of the commercial recordings, including the coverart images, will also be included.

\section{DISTRIBUTION}

We make use of Semantic Web technologies and linked data sources to share our collection. Semantic Web technologies allow flexible and extensible representation and sharing of metadata. We will utilise existing ontologies to share our ground truth annotations of music recordings. This will include Music ontology [8], which deals with music-related information on the Semantic Web, as well as Features, Timeline and Event ontologies. We plan to store our collection at MusicBrainz [1], which provides the most comprehensive crowd-sourced, structured metadata about musical recordings and a reliable and unambiguous music identification for future use.

\section{CONCLUSION}

This paper outlined our initial work on creation of the digital library content to be used for studies of stylistic in-
Table 1: An example of the manual annotation of a tune.

\begin{tabular}{|c|c|c|c|c|}
\hline \multicolumn{5}{|c|}{ Tune Title: Maid on the Green } \\
\hline $\begin{array}{l}\text { Onset } \\
\text { time (s) }\end{array}$ & $\begin{array}{l}\text { Offset } \\
\text { time (s) }\end{array}$ & $\begin{array}{l}\text { Type of } \\
\text { Segment }\end{array}$ & $\begin{array}{l}\text { Note } \\
\text { Identity }\end{array}$ & $\begin{array}{l}\text { Note Fre- } \\
\text { quency }(\mathrm{Hz})\end{array}$ \\
\hline 22.2531 & 22.4000 & note & A5 & 881.731 \\
\hline 22.4102 & 22.5429 & note & B5 & 978.209 \\
\hline 22.5449 & 22.5918 & ct & B5 & 952.079 \\
\hline 22.5898 & 22.7143 & note & A5 & 883.741 \\
\hline 22.7082 & 22.8714 & roll_nt_sl & G5 & 785.254 \\
\hline 22.8857 & 22.9327 & roll_ct & A5 & 837.513 \\
\hline 22.9245 & 23.0000 & roll_nt & G5 & 785.254 \\
\hline 23.0082 & 23.0408 & roll_str & $\mathrm{F} \# 5$ & 759.125 \\
\hline 23.0490 & 23.1714 & roll_nt & G5 & 789.274 \\
\hline 23.1796 & 23.2816 & note & A5 & 877.711 \\
\hline
\end{tabular}

terpretations in Irish traditional flute music. We described the audio recordings and players in our collection and the metadata we are creating, which consists of manual annotations of audio signal as well as of relevant information on the tune and the player. We expect our digital library content to be useful to others working in this domain for developing an awareness of how style is represented and of the creative processes in Irish traditional music as well as preserving cultural heritage.

\section{ACKNOWLEDGMENTS}

This work was supported by the Arts and Humanities Research Council, UK as part of the Transforming Musicology project.

\section{REFERENCES}

[1] MusicBrainz. http://musicbrainz.org.

[2] B. Breathnach. Folk Music and Dances of Ireland. London: Ossian, 1971/1996.

[3] P. M. Brossier. Automatic annotation of musical audio for interactive applications. PhD thesis, Queen Mary, University of London, 2006.

[4] C. Cannam, C. Landone, and M. Sandler. Sonic visualiser: An open source application for viewing, analysing, and annotating music audio files. In Int. Conf. ACM Multimedia, pages 1467-1468, Firenze, Italy, Oct. 2010.

[5] D. Kearney. The solo ensemble: Trends in Irish traditional music recordings by solo artists. In Int. Council for Traditional Music Conf., Limerick, Ireland, 2010.

[6] M. Köküer, P. Jančovič, I. Ali-MacLachlan, and C. Athwal. Automated detection of single- and multi-note ornaments in Irish traditional flute playing. In Int. Society for Music Information Retrieval (ISMIR) Conf., Taipei, Taiwan, Oct. 2014.

[7] G. Larsen. The Essential Guide to Irish Flute and Tin Whistle. Mel Bay Publications, Missouri, USA, 2003.

[8] Y. Raimond, S. Abdallah, M. Sandler, and G. Frederick. The music ontology. In Int. Society for Music Information Retrieval (ISMIR) Conf., pages 311-317, Vienna, Austria, 2004. 